\title{
Pros \& Cons of Using Blackboard Collaborate for Blended Learning on Students Learning Outcomes
}

\author{
Mona M. Hamad ${ }^{1}$ \\ ${ }^{1}$ Department of English, College of Science \& Arts for Girls, King Khalid University, Muhayil, Saudi Arabia \\ Correspondence: Mona M. Hamad, Department of English, College of Science \& Arts for Girls, King Khalid \\ University, Muhayil, Saudi Arabia. Tel: 966-542-34-9145. E-mail: monahamed65@hotmail.com
}

Received: February 13, 2017

Accepted: February 28, $2017 \quad$ Online Published: March 27, 2017

doi:10.5539/hes.v7n2p7

URL: http://doi.org/10.5539/hes.v7n2p7

\begin{abstract}
Blackboard Collaborate was introduced to King Khalid University recently in the last decade, instructors and students were trained to use it in an effective way. The objective of this study is to find pros \& cons of using Blackboard Collaborate for Blended Learning and its effect on students learning outcomes. The researcher used the experimental and descriptive methods to conduct this study; the population of this study was twenty two female-students studying at College of Science \& Arts/Muhayil, English Department in the 5th level who were studying Speech Workshop Course in the 1st semester 2016-2017. Two instruments were used to collect the data of this study: 1) Paper test and electronic test. 2) Students' questionnaire. The findings of this study are: 1) Students' results in the electronic test are much better than the paper test. 2) In spite of students' preference to traditional classroom lectures, the students agreed that using blackboard for blended learning helped them: a) Get lesson-materials or to watch recorded lectures in case they are absent. b) Learn from their classmates' mistakes in discussion blogs. c) Learn according to their learning styles. D) Feel dependent and secure to have regular contact with their instructor and get quick feedback for their questions and confidential tests grade results. The findings above helped to reinforce students' motivation towards learning and affect their learning outcomes positively, however, bad access of net affects using Blackboard Collaborate in blended learning negatively.
\end{abstract}

Keywords: Pros, Cons, blackboard collaborate, blended learning

\section{Introduction}

Wikipedia defined Blended Learning: It is an educational program (formal or informal) that combines online digital media with traditional classroom methods requiring the physical presence of both teacher and student, with some element of student control over time, place, path, or pace. While students still attend "brick-and-mortar" schools with a teacher present, face-to-face classroom practices are combined with computer mediated activities regarding content and delivery. Blended learning is also used in professional development and training settings.

In a blended-learning course, for example, students might attend a class taught by a teacher in a traditional classroom setting, while also independently completing online components of the course outside of the classroom. In this case, in-class time may be either replaced or supplemented by online learning experiences, and students would learn about the same topics online as they do in class, i.e., the online and in-person learning experiences would support and complement one another (Kozma, 2005). Pointed that putting computers into schools is not enough to impact student learning, but certain applications of ICT can positively impact students' knowledge, skills and attitudes, as well as teaching practices, school innovation, and community services.

The E-Learning Deanship (ELD) at King Khalid University was established in the year $1426 \mathrm{H}$ as part of the continuous university efforts to provide the latest scientific methodologies to improve the educational process. Since, the E-Learning Center has performed various activities and roles and had many experiences in deploying technology in education and developing skills and abilities of the University employees.

With the introduction of Blackboard collaborate to King Khalid University in the last decade, instructors and students were trained to use it ineffective way. As a member staff of king Khalid university, I have been using blackboard collaborate for uploading lectures and assignment to help students since 2012, but not as a blended learning, but this year, I have used blackboard collaborate for blended learning after getting permission from my 
university and college administration. Following terms and criteria of evaluation designed to fulfill quality matters of E-Learning Deanship of King Khalid university for teaching electronic or blended course, I used blackboard collaborate for virtual classroom, electronic exam, assignment, blogs, course messages and discussion threads to fulfill all course objectives and to get best desired learning outcomes.

\subsection{Objective of the Study}

Instructors of English language worked hard to motivate students towards learning English; they used different strategies and techniques to attain their objectives. The objective of this study is to find pros and cons of using Blackboard Collaborate for Blended Learning on students' learning outcomes, and getting students' opinions after experiencing blended learning.

\section{Literature Review}

Blended Learning is one of the most modern type of education that combines old and new in one frame of work, it preserves traditional methods, and makes use of technological invention to get students' attention who have already become addicted to digital media in their social life. This also to fulfill the global need to develop traditional methods of teaching to meet the current trends and standards of different education systems.

Saudi Arabia is a vast country, students come from distant places, so blended learning can help those who have problem of transportation, as mentioned before in a blended-learning course, students might make use of learning in a traditional classroom, and make use of online materials provided on blackboard independently by completing online components of the course outside the classroom from any place they might have access to internet.

Larsen (2012) pointed that blended learning affected student perceptions of the ESL writing course and make them feel more responsible for their own learning and take ownership of learning material. Choosri Banditvilai (2016) in his study Enhancing Students Language Skills Through Blended Learning where he used e-learning strategies in parallel with traditional classroom language teaching methods of the four Language learning skills found that online practice is directly beneficial to enhance the four language learning skills as well as autonomous learning and learner motivation. Mustafa Sariepeci, Hasan Cakri (2015) in their study: The Effect of Blended Learning Environments on Student Motivation and Student Engagement found that blended learning environment had meaningful increase in average academic achievement when compared to students in face-to-face learning environment. In addition, blended learning has a medium level effect size on students' levels of academic achievement. Zurita, Hasbun, Baloian, Jerez (2015) in their study: A Blended Learning Environment for Enhancing Meaningful Learning Using 21st Century Skills, found that there is a significant increase in meaningful learning by the end of the course that was supported by blended-learning, their study illustrates the potential that blended-learning environments offer for higher education. Nagwa A. Soliman (2014) in her study: Using E-Learning to Develop EFL Students' Language Skills and Activate their Independent Learning revealed that E-Learning is an essential tool that should be used to supplement the EFL face-to-face class. It includes various activities and resources that if used by the students and monitored by the teacher, it could enhance students' language proficiency and independent learning, to meet world progresses, by utilizing technology to make students interact with the language and motivate them to work independently and thus eventually they become life-long learners. Ruba Obiedat, Lubna Nasir Eddeen and others (2014) in their study: Effect of Blended-Learning on Academic Achievement of Students in the University of Jordan stated that there is a significant and positive impact of blended learning on academic achievement of the students in university of Jordan. Demirer and Sahin (2013) in their study: Effect of Blended Learning Environment on Transfer of Learning: an experimental study, reported that although there is no significant difference between the groups in terms of academic achievement, the students in the blended group are more successful in transferring their knowledge to their projects than the ones in the face-to-face group. In conclusion, the results show that the blended learning approach has a positive effect on the transfer of learning. Jennifer Olson et al. (2011) in their study: An Analysis of E-Learning Impacts \& Best Practices in Developing Countries showed that E-Learning helps to address shortages of teachers, using distant classroom and video conferences. It also addresses the shortage of learning material such as textbooks for students. The material could be made available on hand-held devices such as e-readers or mobile phones. It also improves the quality of education by providing improved informational content and learning approaches. Interactive, communicative E-Learning may promote the development of skills in students (so called "21st Century Skills"). Besides this, it helps to provide students with information and communications technology skills that help graduates to be better equipped to contribute to the knowledge-centered globalized economy of their counties. 


\section{Methodology}

\subsection{Data Collection}

The researcher used experimental and descriptive method to conduct this study.

\subsection{Population}

The population of this study was twenty two female-students studying at College of Science \& Arts/Muhayil, English Department in the 5th level who were studying Speech Workshop Course from English Department in the 1st semester 2016-2017.

\subsection{Instruments of the Study}

Two instruments were used to collect the data of this study:

1) Paper test and electronic test. 2) Students' questionnaire.

\subsection{Reliability and Validity for Student Questionnaire}

To find the validity of the students' questionnaire, the following formula was applied after finding reliability results using Cronbach's Alpha: Validity $=\sqrt{R} \in \mathbb{H l l}_{\mathrm{abl}}=.96$ which is a high degree that reflects that students questionnaire-validity which indicates that the questionnaire is suitable to be used for the study.

\section{Statistics and Results}

\subsection{Tests Results}

The students were given two tests, a paper test after sixth week using traditional classroom methods of teaching and electronic test in thirteenth week using blended learning, and the results were compared. For each test certain chapters are covered. The results were coded using and analyzed using SPSS, the researcher used t-test through t-distribution to find the results, and the table below illustrates the results.

Table 1. Comparison of the electronic test and the paper test results

\begin{tabular}{cccccccc}
\hline Axis & Group & Mean & Std. Deviation & $\mathrm{t}$ & $\mathrm{df}$ & Sig. (2-tailed) & Reality of 0.05 \\
\hline \multirow{2}{*}{ exam } & e test & 17.7727 & 1.34277 & \multirow{2}{*}{ s.923 } & 42 & .001 & significant \\
& paper test & 13.5455 & 3.06637 & & & & \\
\hline
\end{tabular}

From the above table we can read that the value of (t-test) calculated (5.923) degree of freedom (42) and the value of the probability (.001) with reality level (0.05), these statistics approve the significant existence of differences between the electronic test results, and paper test results, for the benefit of electronic test results, which show that learning outcomes after using Blackboard Collaborate for Blended Learning is better.

\subsection{Students' Questionnaire}

A- Figures below illustrate questionnaire results.

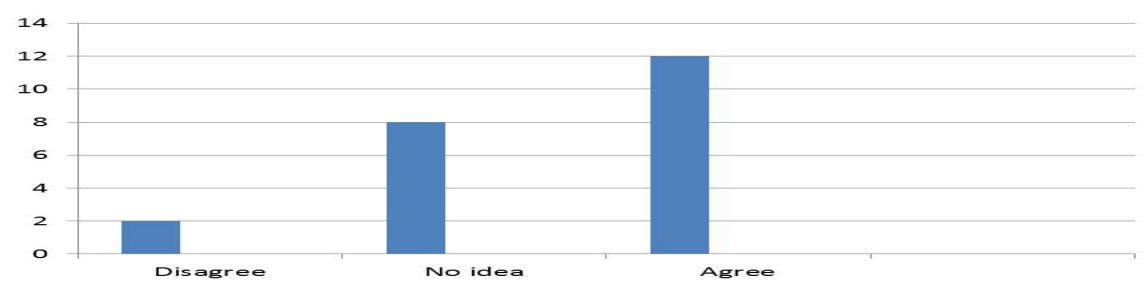

Figure 1. I prefer using traditional classroom lectures to using Blackboard Collaborate for Blended Learning 
In the above figure, two students disagree to the statement, eight students said they had no idea and twelve students agreed to the statement.

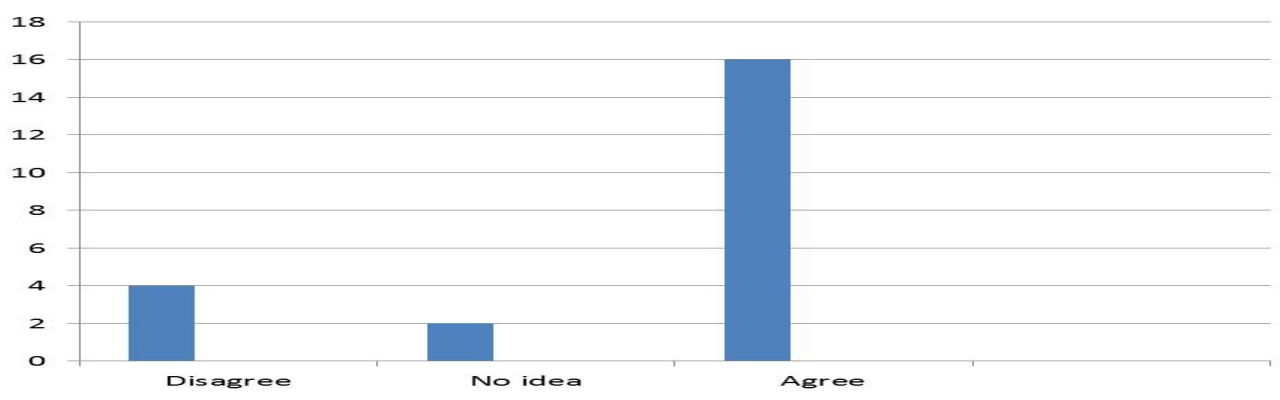

Figure 2. Traditional classroom lectures makes me feel more secure to have my teacher around face to face

In the above figure, four students disagree to the statement, two students said they have no idea and sixteen students agreed to the statement.

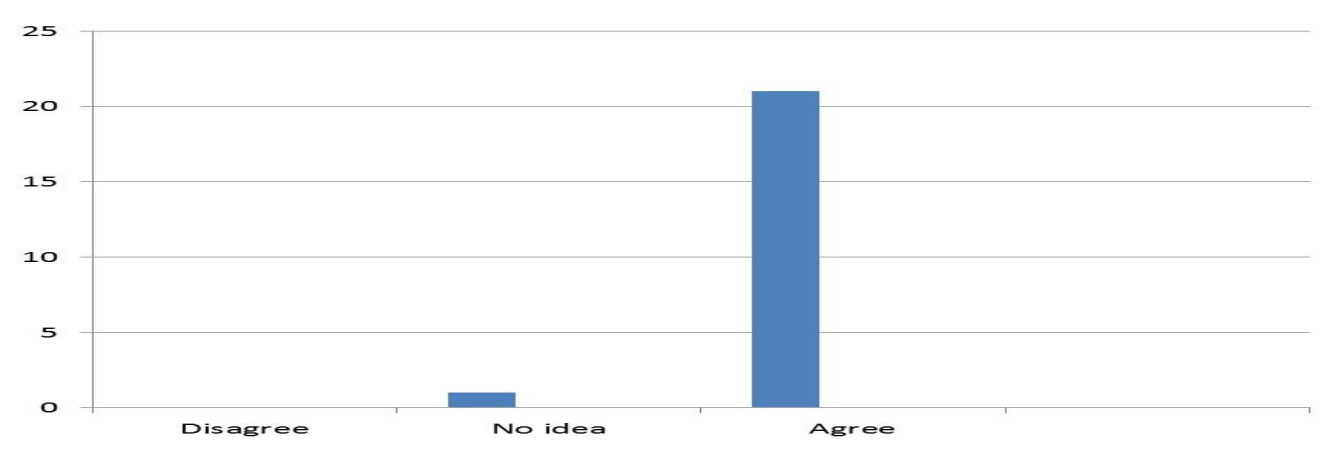

Figure 3. Blackboard Collaborate is helpful because I can access to lectures if I am absent

In the above figure, one students said she had no idea and 21 students agreed to the statement.

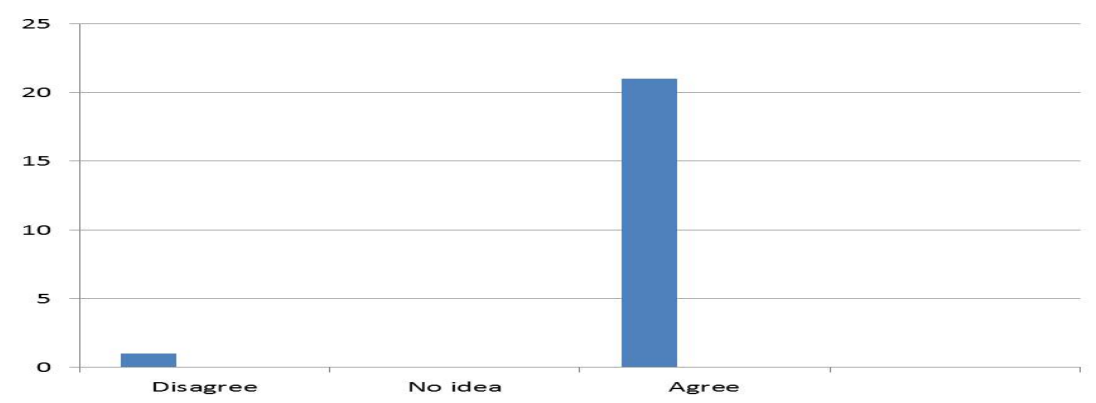

Figure 4. Having lectures on the Blackboard Collaborate is helpful to get and download lectures' materials whenever I want 
In the above figure, one student disagree and twenty one students agreed to the statement.

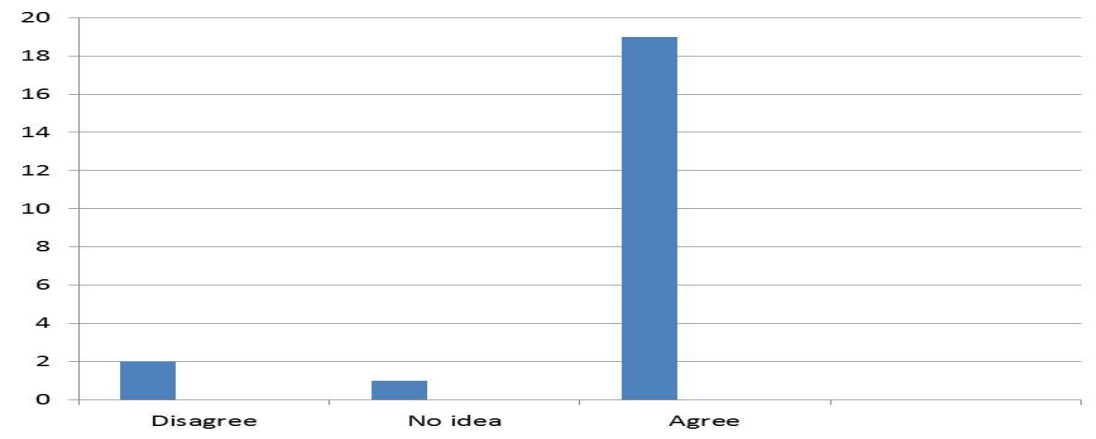

Figure 5. Blogs helped me to develop my language skills from my classmates-posts

In the above figure two students disagree to the statement, one said she had no idea and nineteen students agreed to the statement.

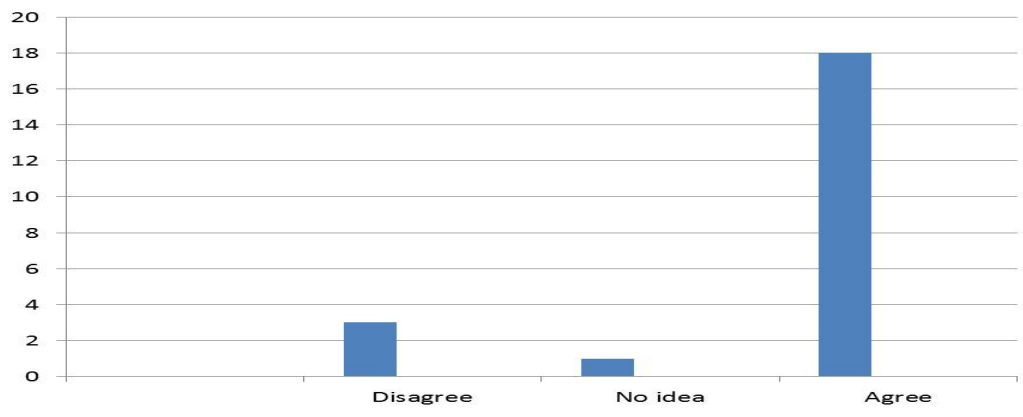

Figure 6. Using Blackboard Collaborate for Blended Learning helped me to learn according to my learning style and time

In the above figure, three students disagree to the statement, one said she had no idea and eighteen students agreed to statement.

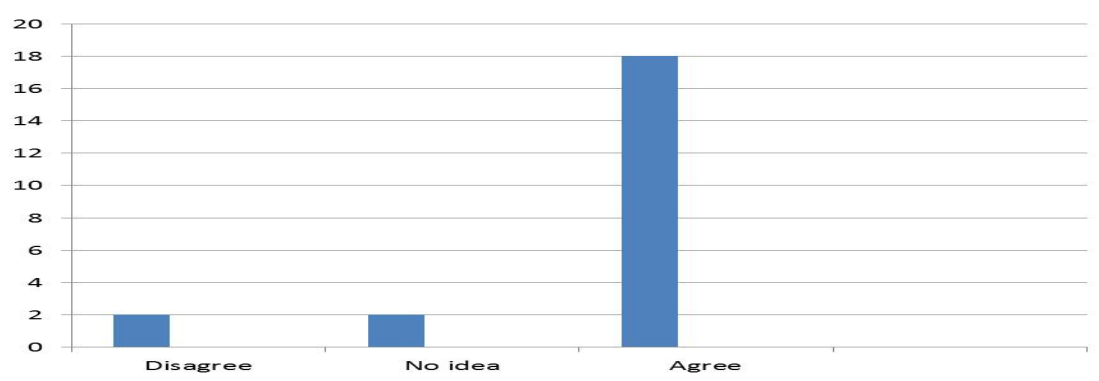

Figure 7. Using Blackboard Collaborate for Blended Learning is helpful because I can re-watch the lectures according to my understanding level 
In the above figure, two students disagree to the statement, two students said they had no idea and eighteen students agreed to the statement.

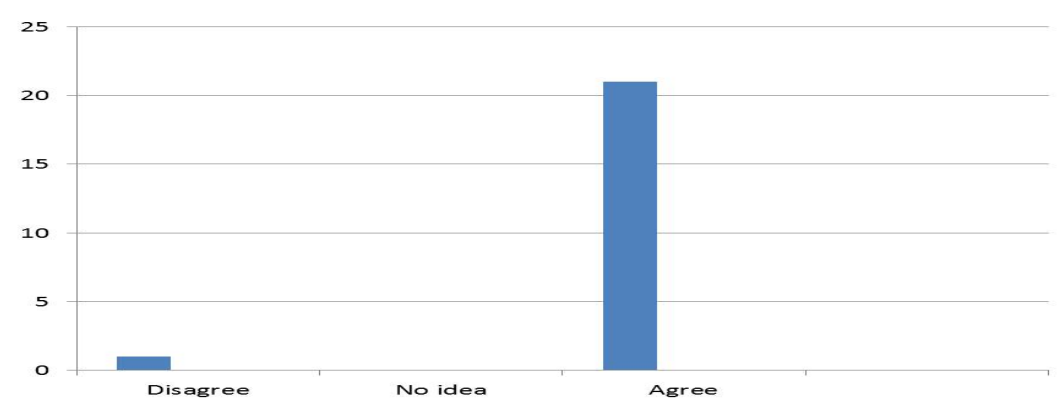

Figure 8. Due to bad net access I can't use the Blackboard Collaborate

In the above figure, one student disagree and twenty one students agreed to the statement.

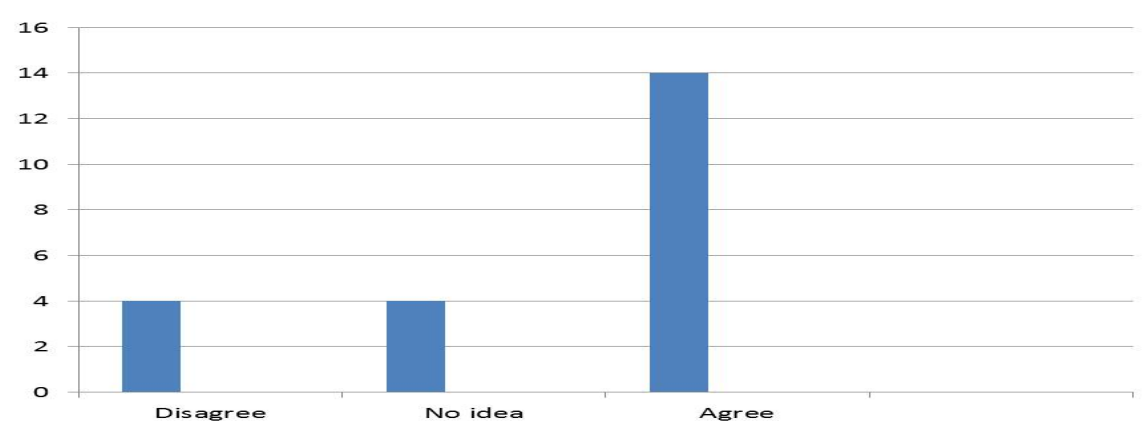

Figure 9. Using Blackboard Collaborate for Blended Learning helped me to feel independent by getting immediate feedback

In the above figure, four students disagree to the statement, four students said they had no idea and fourteen students agreed to the statement.

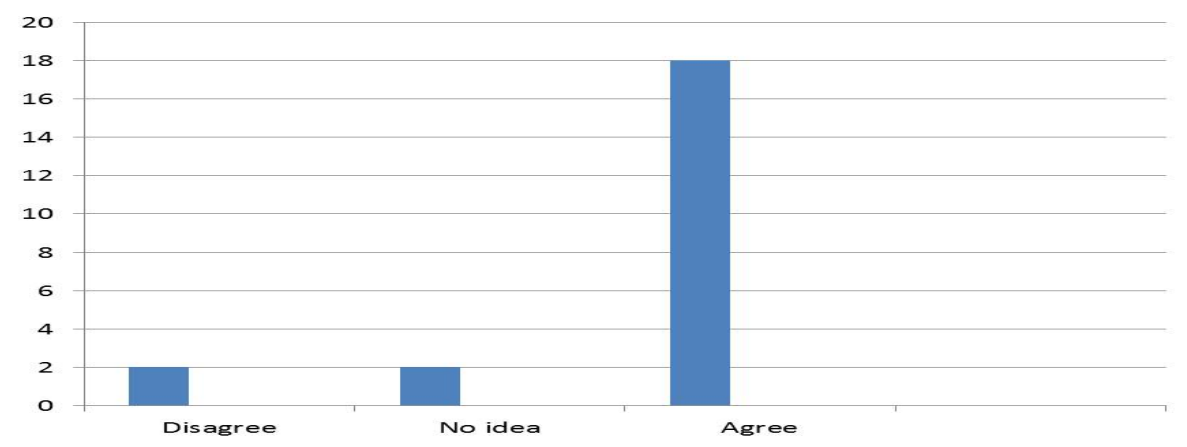

Figure 10. I can contact my instructor and know my grades in a confidential way using Blackboard Collaborate for Blended Learning 
In the above figure, two students disagree to the statement, two students said they had no idea and eighteen students agreed to the statement.

Table 2. Questionnaire analysis

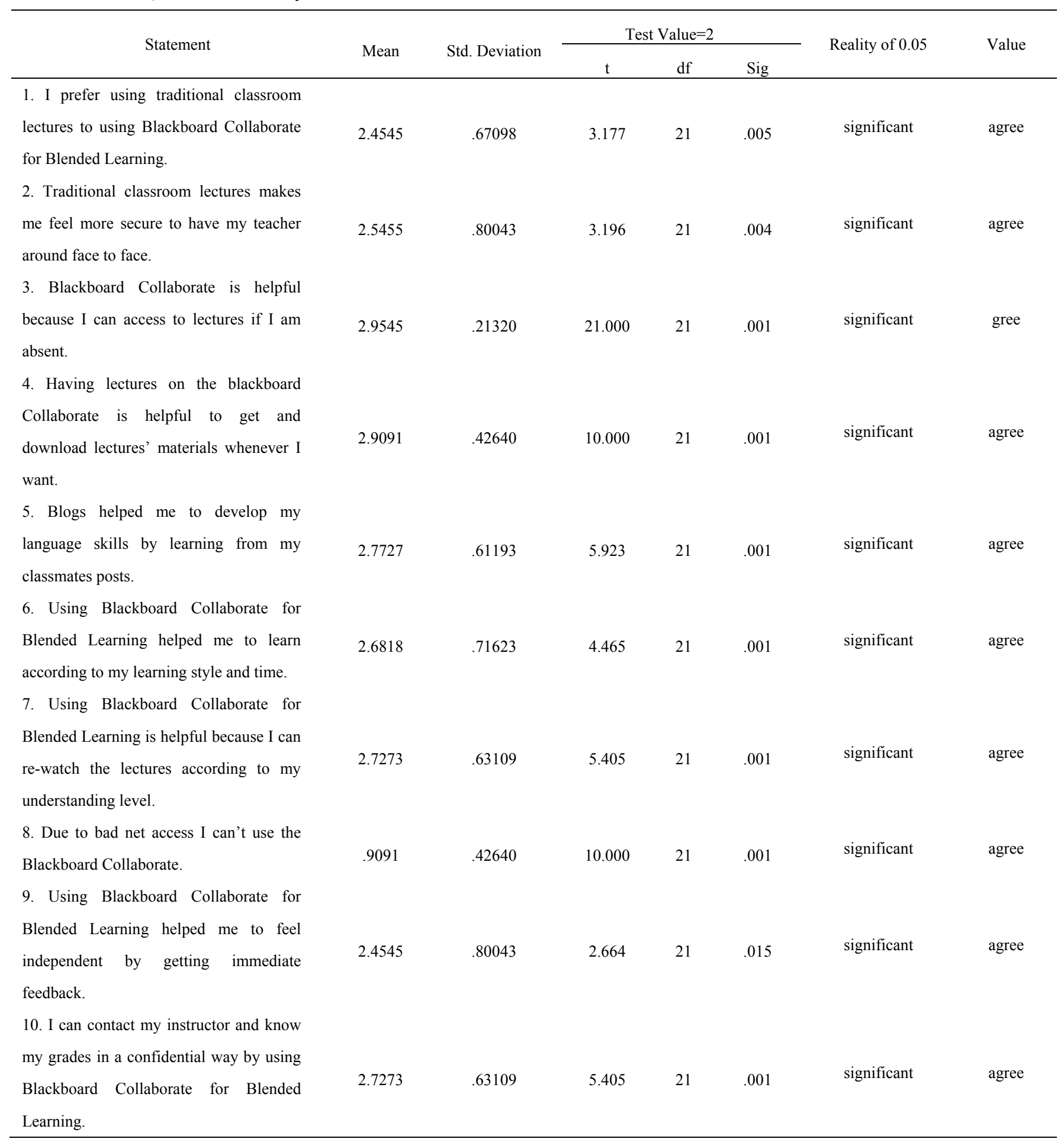




\subsection{Statistics and Data Analysis}

Reading the results in Table 2 above which reflects questionnaire responses that have been manually coded and analyzed using SPSS version 10, using t-test through t-distribution to find results.

Showing results of phrase No (1) in which the value of (T-test) is calculated (3.177) with degree of freedom (21) and the value of the probability (.005), which means that there is a statistical significance of the statistical reality conclusion of the term that says that student prefer using traditional classroom lectures to using Blackboard Collaborate for Blended Learning.

Showing results of phrase No (2) in which the value of (T-test) is calculated (3.196) with degree of freedom (21) and the value of the probability (.004), which means that there is a statistical significance of the statistical reality conclusion of the term that says that students traditional classroom lectures makes me feel more secure to have my teacher around face to face.

Showing results of phrase No (3) in which the value of (T-test) is calculated (21.000) with degree of freedom (21) and the value of the probability (.001), which means that there is a statistical significance of the statistical reality conclusion of the term that says that students think Blackboard Collaborate is helpful because they can access to lectures if they are absent.

Showing results of phrase No (4) in which the value of (T-test) is calculated (10.000) with degree of freedom (21) and the value of the probability (.001), which means that there is a statistical significance of the statistical reality conclusion of the term that says that students approve that having lectures on the Blackboard Collaborate is helpful to get and download lectures' materials whenever they want.

Showing results of phrase No (5) in which the value of (T-test) is calculated (5.923) with degree of freedom (21) and the value of the probability (.001), which means that there statistical significance of the statistical reality conclusion of the term that says that students approve that blogs helped them develop their language skills by learning from their classmates posts.

Showing results of phrase No (6) in which the value of (T-test) is calculated (4.465) with degree of freedom (21) and the value of the probability (.001), which means that there statistical significance of the statistical reality conclusion of the term that says that students agreed using Blackboard Collaborate for Blended Learning helped them to learn according to their learning style and time.

Showing results of phrase No (7) in which the value of (T-test) is calculated (5.405) with degree of freedom (21) and the value of the probability (.001), which means that there statistical significance of the statistical reality conclusion of the term that says that students agreed using Blackboard Collaborate for Blended Learning is helpful because they can re-watch the lectures according to their understanding level.

Showing results of phrase No (8) in which the value of (T-test) is calculated (10.000) with degree of freedom (21) and the value of the probability (.001), which means that there statistical significance of the statistical reality conclusion of the term that says that students can't always use the blackboard collaborate.

Showing results of phrase No (9) in which the value of (T.test) is calculated (2.664) with degree of freedom (21) and the value of the probability (.015), which means that there statistical significance of the statistical reality conclusion of the term that says that using Blackboard Collaborate for Blended Learning helped students to feel independent by getting immediate feedback.

Showing results of phrase No (10) in which the value of (T-test) is calculated (5.405) with degree of freedom (21) and the value of the probability (.001), which means that there statistical significance of the statistical reality conclusion of the term that says that students can contact instructor and know their grades in a confidential way by using Blackboard Collaborate for Blended Learning.

\subsection{Discussion of Results}

After doing statistical procedure, the results of the student's questionnaire were:

1) Students prefer using traditional classroom lectures to using Blackboard Collaborate for Blended Learning.

2) Students prefer using traditional classroom lectures to using Blackboard Collaborate for Blended Learning support.

3) Students think Blackboard Collaborate is helpful because they can access to lectures if they are absent agrees with study of Jennifer Olson et al. (2011).

4) Having lectures on the Blackboard Collaborate is helpful to get and download lectures' materials whenever students want, this finding support (Nagwa, 2014), however, it disagrees with Demirer and Sahin's finding. 
5) Blogs helped me to develop my language skills by learning from my classmates-posts, this result agrees with Nagwa A. Soliman's (2014) finding, but disagrees with Demirer and Sahin's finding.

6) Using Blackboard Collaborate for Blended Learning helped students to learn according to their learning style and time, this result supports both Ruba and Lubna (2014) and Mustafa, Hasan's (2015) findings.

7) Using Blackboard Collaborate for Blended Learning helped students to learn according to their understanding level, this result does not only agree with Ruba Obiedat et al. (2014) study finding, but also agrees with Mustafa and Hasan's (2015) finding.

8) Students can't always use the Blackboard Collaborate due to bad access of net.

9) Using Blackboard Collaborate for Blended Learning helped students to feel independent by getting immediate feedback, this result agrees with Larsen (2012) and Demirer and Sahin's (2013) finding.

10) Students can contact instructor and know their grades in a confidential way by using Blackboard Collaborate for Blended Learning, this result agrees with Choosri Banditvilai's (2016) study finding.

\section{Conclusion}

If we divide the above results to pros and cons we will find that using Blackboard Collaborate for Blended Learning have more pros than cons. From these pros, students using electronic test got better learning outcomes than those who used paper test, also students questionnaire results showed that students are satisfied of using Blackboard Collaborate and Blended Learning as it is helpful to them, they can access, download lectures and learning materials any time they want, they feel confident, confidential by having their exam results individually, moreover, they can learn according to their learning styles, and they can learn from their mates-posts, however, using Blackboard Collaborate for Blended Learning cons are due to the bad access to internet which doesn't help the students to retain their learning material when they want, moreover, the students need to be aware of the advantages of using Blackboard Collaborate for Blended Learning as some students still believe that traditional classroom is more practical.

\section{Recommendations}

We can't deny that face to face lectures has its advantages but we have to support using Blackboard Collaborate for Blended Learning as much as possible to support education technology and make use of resources that King Khalid University provides to staffs, moreover we have to prepare our students for further studies inside and outside the country to meet the global development in education system around the world, we should prepare our students to compete, not only inside Saudi Arabia, but also outside it, anywhere around the globe.

Using Blackboard Collaborate for Blended Learning can help to solve transport problem of ladies who can't reach colleges, and can make education attainable to every one regardless of age or place, also it can help to solve the problem of few instructors for specific subjects.

To overcome cons of using Blackboard Collaborate for Blended Learning, we have to activate and increase Electronic Labs in colleges, build electronic club in each city in central places with good net access, to be used by students outside the colleges to help those have problems in their areas.

\section{References}

Banditvilai, C. (2016). Enhancing Students' Language Skills through Blended Learning. The Electronic Journal of e-Learning, 14(3), 220-229.

Demirer, V., \& Sahin, I. (2013). Effect of blended learning environment on transfer of learning: An experimental study. Journal Computer Assisted Learning, 29(6), 518-529. https://doi.org/10.1111/jcal.12009

Jennifer, O. et al. (2011). An Analysis of e-Learning Impacts \& Best Practices in Developing Countries. Michigan State University.

Kozma, R. B. (2005). Monitoring and evaluation of ICT for education impact: A review. In D. A. Wagner, B. Day, T. James, R. B. Kozma, J. Miller, \& T. Unwin (Eds.), Monitoring and Evaluation of ICT in Education Projects: A Handbook for Developing Countries. World Bank/Info Dev. Retrieved from http://www.infodev.org/en/Publication.9.html

Larsen, L. J. (2012). Teacher and Student Perspectives on a Blended Learning Intensive English program writing course (Graduate Thesis and Dissertation). Iowa State University, Ames.

Mustafa, S. H. C. (2015). The Effect of Blended Learning Environments on Student Motivation and Student Engagement: A Study on Social Studies Course. Journal of Education and Science, 40(177), 203-216. 
Nagwa, A. S. (2014). Using E-Learning to Develop EFL Students' Language Skills and Activate Their Independent Learning. Creative Education, 5, 752-757. https://doi.org/10.4236/ce.2014.510088

Ruba, O., \& Lubna, N. E. (2014). Effect of Blended-Learning on Academic Achievement of Students in the University of Jordan. International Journal of Emerging Technologies in Learning, 9(2).

Zurita, G., Hasbun, B., Baloian, N., \& Jerez, O. (2015). A Blended Learning Environment for Enhancing Meaningful Learning Using 21st Century Skills. In G. Chen, V. Kumar, R. K. Huang, \& S. Kong (Eds.), Emerging Issues in Smart Learning. Lecture Notes in Educational Technology, Springer, Berlin, Heidelberg. https://doi.org/10.1007/978-3-662-44188-6_1

\section{Appendix}

Appendix 1. Students questionnaire

Dear students,

This questionnaire is an instrument of data collection to reflect your experience of using Blackboard Collaborate for Blended Learning blended learning, please put a (*) in the column of option that describe your point of view.

Thanks for your collaboration.

Dr. Mona M. Hamad

\begin{tabular}{|c|c|c|c|c|}
\hline No & Statement & agree & No idea & disagree \\
\hline 1 & $\begin{array}{l}\text { I prefer using traditional classroom lectures to using Blackboard } \\
\text { Collaborate for Blended learning. }\end{array}$ & & & \\
\hline 2 & $\begin{array}{l}\text { Traditional classroom lectures makes me feel more secure to have my } \\
\text { teacher around face to face. }\end{array}$ & & & \\
\hline 3 & $\begin{array}{l}\text { Blackboard Collaborate is helpful because I can access to lectures if I am } \\
\text { absent. }\end{array}$ & & & \\
\hline 4 & $\begin{array}{l}\text { Having lectures on the blackboard Collaborate is helpful to get and } \\
\text { download lectures' materials whenever I want. }\end{array}$ & & & \\
\hline 5 & $\begin{array}{l}\text { Blogs helped me to develop my language skills from my classmate's } \\
\text { posts. }\end{array}$ & & & \\
\hline 6 & $\begin{array}{l}\text { Using Blackboard Collaborate for Blended Learning helped me to learn } \\
\text { according to my learning style and time. }\end{array}$ & & & \\
\hline 7 & $\begin{array}{l}\text { Using Blackboard Collaborate for Blended Learning is helpful because I } \\
\text { can re-watch the lectures according to my understanding level. }\end{array}$ & & & \\
\hline 8 & Due to bad net access I can't use the Blackboard Collaborate any time. & & & \\
\hline 9 & $\begin{array}{l}\text { Using Blackboard Collaborate for Blended Learning helped me to feel } \\
\text { independent by getting immediate feedback. }\end{array}$ & & & \\
\hline 10 & $\begin{array}{l}\text { I can contact my instructor and know my grades in a confidential way } \\
\text { using Blackboard Collaborate for Blended Learning. }\end{array}$ & & & \\
\hline
\end{tabular}

\section{Copyrights}

Copyright for this article is retained by the author(s), with first publication rights granted to the journal.

This is an open-access article distributed under the terms and conditions of the Creative Commons Attribution license (http://creativecommons.org/licenses/by/4.0/). 